\title{
Gold Acyl Complex Formation and Decarbonylation during Indene Synthesis from Catalytically Active Vinylidene Complexes
}

\author{
Helgard G. Raubenheimer
}

Trost and others, ${ }^{[1]}$ particularly employing the metals ruthenium, rhodium, molybdenum and tungsten, established the formation of catalytic vinylidene complexes from alkynes and their use in selective addition reactions. Zhang and coworkers ${ }^{[2]}$ and Hashmi and coworkers, ${ }^{[3]}$ independently, extended the field to include carbophilic gold complexes as precatalysts for dual activation of dialkynes. ${ }^{[4]}$ Despite the high affinity of gold(I) for alkynes as ligands, no tautomeric vinylidene complexes have yet been isolated. Amongst the many reactions known for gold complexes no carbonyl insertion has yet been found and, consequently, acyls of this metal are rare and have to be prepared by indirect methods. ${ }^{[5]}$ Related alkoxy carbene complexes of the Fischer type are also uncommon. ${ }^{[6]}$

In a significant advance based on chemical intuition, precedent and serendipity, Hashmi and coworkers have now established that selected diyne systems in the presence of a gold catalyst can be converted directly into a variety of indenes (Scheme 1) simply by nucleophilic reaction with water. ${ }^{[7]}$ In the proposed catalytic cycle, the first important new transformation occurs between intermediate, catalytically active gold vinylidenes, initially conjugated to a vinyl gold substructure, and acyl complexes of gold, as summarized in Scheme 2.

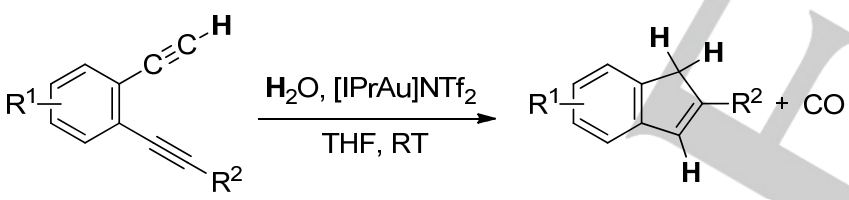

Scheme 1. Gold catalysed indene formation from diynes and water by ring closure, $\mathrm{CO}$ elimination and triple proton transfer.<smiles>[R]C1=C([Z])c2cc[Z1]([H])cc2C1=[Al]</smiles>

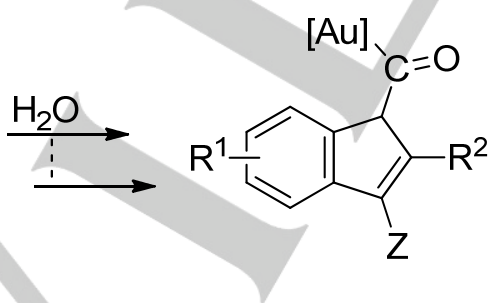

$[\mathrm{Au}]=\mathrm{IPrAu}$

$\mathrm{Z}=[\mathrm{Au}]$ or $\mathrm{H}$

Scheme 2. The exact number of steps for the conversion of intermediate vinylidenes into acyl complexes is unknown.

[*] Prof HG Raubenheimer

Department of Chemistry and Polymer Science Stellenbosch University

Private Bag X1, Matieland, 7602, (South Africa)

E-mail: hgr@sun.ac.za
Related conversions are known for vinylidene catalytic systems with other metals and have been studied in detail. Aldehyde products are formed in a final reductive elimination step that involves a metal hydride (Scheme 3)..$^{[1]}$ Hydride complex formation of neutral, already linear gold(I) compounds is not known and highly unlikely to occur in catalytic cycles. ${ }^{[8]}$ Interestingly, with allylic alcohols as nucleophiles, ketones are produced in very useful ruthenium-catalyzed reactions. Such reactions were employed successfully in targeted syntheses by Trost. $^{[9,1}$

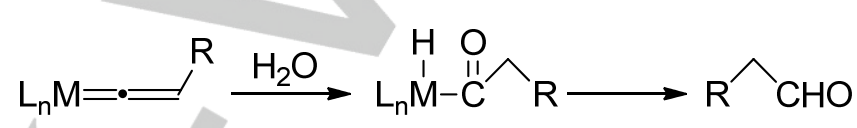

Scheme 3. Generalized hydration of metal vinylidene intermediates to form aldehydes (hydroxycarbene intermediate not shown)

Hashmi and coworkers, ${ }^{[7]}$ when studying the trapping of intermediate vinylidene complexes by water, found that aldehydes were not formed from the acyl intermediates. In the first examples for gold chemistry, also unprecedented in vinylidene-mediated catalysis, decarbonylations occurred consistently allowing subsequent protonations and affording the indene products (Scheme 4). Notably, intermediate ruthenium allenylidene species undergo decarbonylation upon hydration. ${ }^{[10]}$<smiles>[R]C1=Cc2cc[R1](CC(C)C)cc2C1</smiles>

\section{$\mathrm{Z}=[\mathrm{Au}]$ or $\mathrm{H}$}

Scheme 4. Stepwise conversion of complex acyl intermediates into indenes; compare Scheme 1 for the origin of the protons.

An excellent related literature precedent offering most of the important steps postulated by Hashmi and coworkers, is found in the work of Bianchini et al. ${ }^{[11]}$ where ruthenium complexes were used under stoichiometric conditions. Notably, these authors as well as Trost and others (on the basis of indirect evidence), ${ }^{[1,12]}$ prefer to include unstable hydroxycarbene intermediates as preliminaries to acyl formation. Such complexes are mentioned in the introduction to the current paper by Hashmi and coworkers, ${ }^{[7]}$ but they are not included in the final catalytic cycle.

A challenge emerging from the latest breakthrough by Hashmi and coworkers is to demonstrate that the reverse 
reaction, namely carbonyl insertion into an $\mathrm{Au}-\mathrm{C}$ bond, also takes place. Such an achievement would ensure a paradigm shift regarding the hitherto accepted insignificant role of carbonyl chemistry in homogeneous gold catalysis. The results described by them also send out a message to synthetic chemists to find other examples of $\mathrm{CO}$ insertion/deinsertion in $\mathrm{Au}-\mathrm{C}$ bonds. An ultimate goal would then be to eventually fully understand the intimate mechanism of such reactions and its influence on the coordination chemistry of (normally) linear $\mathrm{Au}(\mathrm{I})$ complexes. As has been pointed out by the authors and also indicated in Schemes 2 and 4 , a number of uncertainties regarding the proposed catalytic cycle remain and these should be investigated in greater detail in future. In particular, the precise stages at which the three protonation steps occur should be identified. Optimization of designed precatalysts for different diyne substrates to ensure satisfactory yields as well as more information about functional group tolerances, would further contribute to making the synthetic process even more useful to a wider chemical community. ${ }^{[13]}$

Keywords: gold catalysis • gold vinylidenes $\cdot$ gold acyls • indenes $\cdot$ decarbonylation
[1] B. M. Trost, A. McClory, Chem. Asian J. 2008, 3, 164-194.

[2] L. Ye, Y. Wang, D. H. Aue, L. Zhang, J. Am. Chem. Soc. 2012, 134, 31-34.

[3] A. S. K. Hashmi, I. Braun, M. Rudolph, F. Rominger, Organometallics 2012 31, 644-661.

[4] A. S. K. Hashmi, Acc. Chem. Res. 2014, 47, 864-876.

[5] H. G. Raubenheimer, S. Cronje, Chem. Soc. Rev. 2008, 37, 1998-2011.

[6] H. G. Raubenheimer, S. Cronje, C. Strasser, Dalton Trans. 2009, 8145-8154.

[7] J. Bucher, T. Stößer, M. Rudolph, F. Rominger, A. S. K. Hashmi, Angew. Chem. Int. Ed. 2015, 54, 1666-1670; Angew. Chem. 2015, 127, 1686-1690.

[8] H. Schmidbaur, H. G. Raubenheimer, Chem. Soc. Rev. 2014, 43, 345380.

[9] B. M. Trost, J. A. Flygare, Tetrahedron Lett. 1994, 35, 4059-4062.

[10] S. Datta, C.-L. Chang, K.-L. Yeh, R.-S. Lui, J. Am. Chem. Soc. 2003, 125, 9294-9295.

[11] C. Bianchini, J. A. Casares, M. Peruzzini, A. Romerosa, F. Zanobini, J. Am. Chem. Soc. 1996, 118, 4585-4594.

[12] M. I. Bruce, Chem. Rev. 1991, 91, 197-257.

[13] a) A. S. K. Hashmi, F. D. Toste, Modern Gold Catalyzed Synthesis, Wiley-VCH, Weinheim, 2012; b) F. D. Toste, V. Michelet, Gold Catalysis - An Homogeneous Approach, Imperial College Press, London, 2014. 
Entry for the Table of Contents (Please choose one layout)

Layout 1:

\section{HIGHLIGHT}

In a golden moment targeted gold acyl complexes generated from dialkynes via vinylidene intermediates decarbonylate to form indenes by proto-aurolysis.

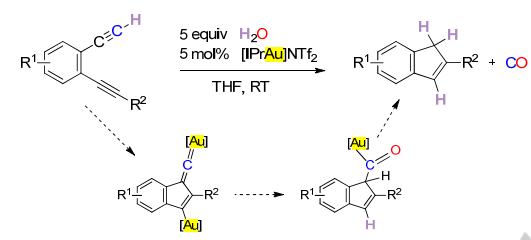

H. G. Raubenheimer

Page No. - Page No.

Gold Acyl Complex Formation and

Decarbonylation during Indene

Synthesis from Catalytically Active

Vinylidene Complexes

Layout 2:

\section{HIGHLIGHT}

((Insert TOC Graphic here))

Text for Table of Contents
Author(s), Corresponding Author(s)*

Page No. - Page No.

Title 